\title{
A Short Review on the Development of Salt Tolerant Cultivars in Rice
}

\author{
Samiullah Khan, Muhammad Arshad Javed, Nusrat Jahan, Fazilah Abd Manan \\ Faculty of Biosciences and Medical Engineering, Universiti Teknologi Malaysia, Skudai, 81310, \\ Johor Bahru, Johor, Malaysia
}

\begin{tabular}{l} 
Article Info \\
\hline Article history: \\
Received Mar 10, 2016 \\
Revised Apr 25, 2016 \\
Accepted May 15, 2016 \\
\hline
\end{tabular}

\section{Keyword:}

Physiology

QTLs

Rice

Salinity

Stress

\begin{abstract}
Rice is staple food for half of the world. With a population of almost 9.6 billion by the year 2050, there is a dire need of developing techniques to improve the crop plants, not only in terms of better yield but also to withstand harsh environmental conditions and stresses like drought, temperature, flood and salinity. Salinity is second to drought stress and hence it is very important to develop crops tolerant to salinity stress. This review discusses the mechanisms of salt tolerance and the recent developments in understanding the complex tolerance phenomena. One way to address the salinity issue is to develop tolerant rice varieties using conventional and modern breeding techniques for which screening the rice germplasm for the varieties with desired traits is critical. Conventional methods to develop tolerant rice varieties are discussed along with modern biotechnology techniques are also discussed. Quantitative Trait Loci (QTL) and Marker Assisted Selection (MAS) are promising techniques. In addition to these modern techniques, some recent developments in the fields of transgenic plants, haploid breeding and Somaclonal variations have also been discussed. The limited knowledge about molecular and genetic mechanisms to tolerate abiotic stresses however is a barrier to efficiently develop tolerant cultivars. A combination of conventional and modern biotechnology techniques could possibly open up the new ways.
\end{abstract}

Copyright (c) 2016 Institute of Advanced Engineering and Science. All rights reserved.

\section{Corresponding Author:}

Muhammad Arshad Javed,

Faculty of Biosciences and Medical Engineering,

Universiti Teknologi Malaysia (UTM),

Skudai, 81310, Johor Bahru, Johor, Malaysia.

Email: majaved@fbb.utm.my

\section{INTRODUCTION}

Rice is critical for food security in so many of the countries. More than 50 percent of the world's population is dependent upon rice for 80 percent of its diet [1]. World's population has exceeded 7 billion and rice consumers will be doubled by the year 2020 [2]. As the population is increasing, rice production also needs to continue to increase in coming decades to meet the food demands [3],[4]. One of the main challenges to raise the food production is to overcome the environmental stress such as temperature, drought, flood and salinity [5]. Rice is considered as salt-sensitive crop and soil salinity is one of the most important abiotic stresses damaging the rice yield [1],[6]. Salinity is one of the most important environmental stresses affecting the productivity of most field crops [7]. A better understanding of mechanisms underlying the salinity tolerance in plants will significantly help in developing varieties with enhanced salinity tolerance.

Earth is a salty planet, with most of its water containing about $30 \mathrm{~g}$ of sodium chloride per litre. More than 800 million hectares of land throughout the world are salt affected [8],[9] which include the land on which crops are, or might be, grown. In the mid-1980s an estimated 1.3 million ha of rice-growing areas were affected by salinity or alkalinity. It is estimated that some 9-12 million ha are affected all around the 
world [1],[10]. Salinity is widespread in coastal areas, and salinity, alkalinity, or sodicity is widespread in inland areas of arid regions [11],[12]. There are different factors of salinity for different kind of lands. For inland salinity, it is due to salt deposits present in the soil or bedrock or from the use of salty irrigation water. In this soil, rice cannot be grown without good-quality irrigation water.

For coastal salinity, it is due to tidal intrusion where the highly saline sea water is mixed up with the fresh water making it saline to toxic levels [13]-[15]. The other cause of accumulation of salts especially sodium chloride to irrigated soils is the deposition of oceanic salts carried in wind and rain.Rainwater contains $6-50 \mathrm{mg} / \mathrm{kg}$ of sodium chloride; the concentration decreases with distance from the coast [8]. Climate change is also expected to affect the soil salinity.Global warming causes increased $\mathrm{CO}_{2}$ levels, causing abrupt changes in climate resultingin storms, droughts and heavy rainfalls. These harsh weather conditions may cause flooding and relevant extreme weather conditions. Slowly and steadily increasing sea levels are another possible cause of flood risk and areas ambient to estuaries receive high amounts of salts causing stresses for the crops especially rice [16]-[19]. Salinity affects almost all processes of the plant [11],[20],[21] and rice plants react differently at different life stages to salinity [22] suggesting that different mechanisms are involved for salinity tolerance in rice at different life stages.

High salt stress disrupts homeostasis in plants and ion distribution at both the cellular and the wholeplant levels. This is because of the osmotic effects by high ionic concentrations, competitive interference with nutrient uptake and of toxic effects within the plant tissue. Drastic changes in ion and water homeostasis lead to molecular damage, growth arrest and even death [23]-[25]. Since agricultural land is a limited source, therefore, increasing the salinity resistance of rice is a necessary alternative to increase the food production to meet the food demand [26]. Many excellent reviews have focused on stress tolerance, mechanisms to develop stress tolerant crop plants, and particular modern technologies to enhance stress tolerance in economically important crop plants [27]-[31].

This review provides an insight into the mechanisms of salt tolerance, screening strategies for salt tolerance and developing salt tolerant cultivars with special emphasis on rice. It focuses on recent studies on conventional and modern breeding techniques, transgenic approaches and double haploids and somaclonal variations. Tissue culture techniques like anther culture, protoplast fusion and culture, leaf culture, root culture, immature embryo culture and mature seed culture are also important techniques in order to induce variations in plants [32]-[34]. This review also provides comprehensive information to the scientific community for further efforts in combining conventional and modern approaches to develop salt tolerant rice plants/cultivars.

\section{MECHANISMS OF SALT TOLERANCE}

Salinity tolerance is a complex trait and it is often accompanied by other stresses like high temperatures and flooding. Over the years, plants have developed certain mechanisms to cope high salinity levels. A variety of cell signalling cascades and metabolic pathways involving several transcription factors are involved [35]. Soil salinity stresses plants in two ways. High concentrations of salts in the soil make it harder for roots to extract water, and high concentrations of salts within the plant can be toxic [8],[9]. Figure 1 shows different types of salt stress mechanisms found in plants and some of their effects.

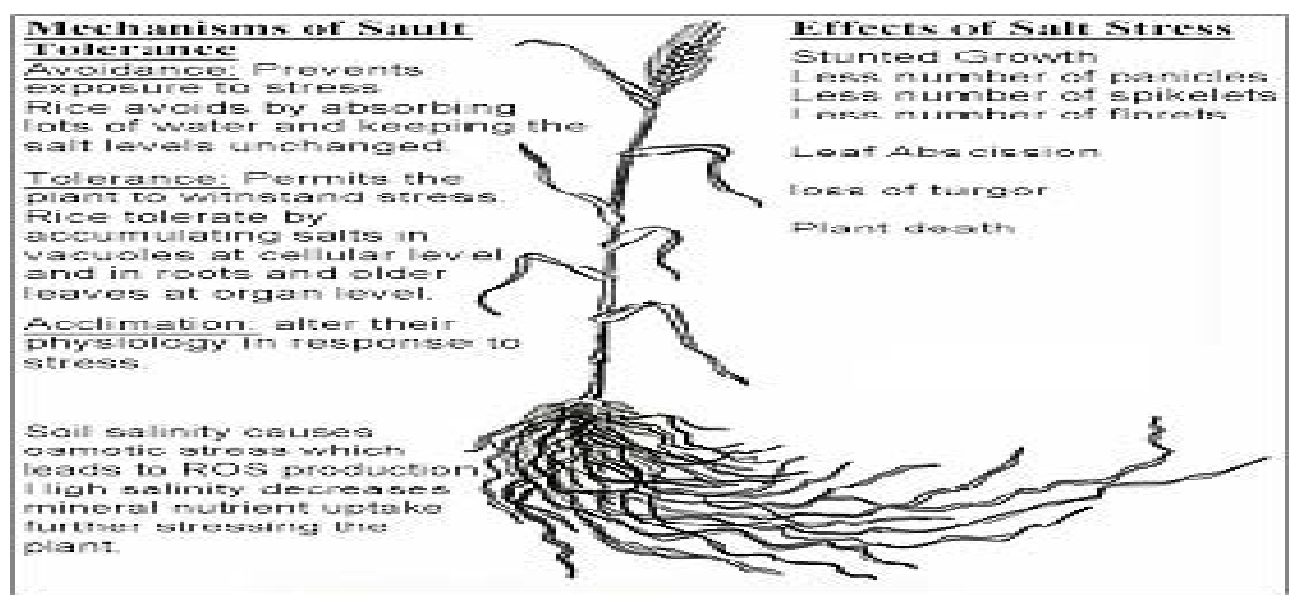

Figure 1. Salt stress mechanisms and effects of salt stress 
Earlier studies conducted under controlled conditions reported that salt injury in rice plantis caused by both osmotic imbalance and accumulation of chloride (CI) ions [36]. Recent studies, however, indicated that it is $\mathrm{Na}+$ which plays its damaging role [37]. Plants respond to salinity in two phases. First phase is a rapid osmotic phase that inhibits growth of young leaves, and second phase is a slower ionic phase that accelerates senescence of mature leaves[38]-[40]. Plant adaptations to salinity can be categorized into three types, which are: osmotic stress tolerance, $\mathrm{Na}^{+}$or $\mathrm{Cl}^{-}$exclusion, and the tolerance of tissue to accumulated $\mathrm{Na}^{+}$or $\mathrm{Cl}^{-}[8]$.

Salt injury score (SIS) is a complex physiological trait related to ion concentration or quantity and to osmosis. According to [41], under salt stress, SIS was correlated with sodium contents in shoot, not in the root. It is suggested that sodium contents are build-up in shoot, due to increased transport of $\mathrm{Na}^{+}$ions from the root to the shoot in external high concentration, which subsequently led to leaves damages. This is because of the re-translocation from shoot to root is insignificant than that from root to shoot [42]. However, the potassium contents in both shoot and root were not correlated with SIS. These results suggested that the high potassium contents did not directly damage leaves [43],[44].

\subsection{Tolerance at different life stages in rice}

It has been observed that out of two main subspecies of rice, indica is more tolerant than japonica [45]. Naturally these indica rice varieties have evolved certain mechanisms to withstand levels that proved to be lethal for japonica varieties. As salinity is a complex trait involving a number of genes, it is a challenging task to first identify all of them and then manipulate and exploit them. This situation becomes complex when the same species behaves differently to same saline conditions in different life stages. Evaluating tolerance is complex because of variation in sensitivity to salt during the life cycle [46]. Salt tolerance comparison between germination and growth stages is difficult because different criteria are used to evaluate plant responses [47]. Indica and japonica rice varieties have been studied at seedling stage for salinity tolerance [48] and it was found that indica varieties were tolerant than japonica and they were better $\mathrm{Na}$ excluders, maintain a low $\mathrm{Na} / \mathrm{K}$ ratio and absorbed high $\mathrm{K}$ while japonica varieties were sensitive.

Several studies indicated that rice is tolerant during germination, becomes very sensitive during early seedling stage (2-3 leaf stage), gains tolerance during vegetative growth stage, becomes sensitive during pollination and fertilization, and then becomes increasingly more tolerant at maturity [49]-[52]. Ripening appears to be less affected by salinity [36],[47],[1],[24].

\section{SCREENING FOR SALINITY TOLERANCE}

There are thousands of rice varieties available with their unique properties. A diverse rice germplasm with significant varietal differences is available as pool for developing screening techniques. These techniques are important to select varieties for breeding purposes. These techniques should be easy, efficient, reproducible and economically feasible. Rice is grown under different field conditions where it is subjected to different types of stress conditions, right from germination to maturity. Salinity being one harmful and most studied type of stress damages the rice plants in so many different ways. Longer exposure to salinity results in accumulation of $\mathrm{NaCl}$ in older leaves [53] which affects the photosynthesis rate significantly. It also disturbs the overall metabolism of the plant and damages it [54]-[56]. Salinity also affects the chloroplast activities [57]. Screening under field conditions is difficult due to variability of salinity within fields, stress heterogeneity, presence of other soil-related stresses, and influence of environmental factors such as temperature, relative humidity, and solar radiation. These complexities, together with the degree of control of salinity and reproducibility, cause difficulties in developing reliable methods of screening [46],[58].

However, there has been considerable effort directed at selection for salinity resistance in rice [46],[59],[1],[24]. Thousands of rice varieties have been developed recently using modern techniques like marker assisted selection. These varieties are resistant to several stresses like drought, cold, light and stresses coming from poor soils especially salinity and toxic metals. Table 1 shows some of the rice varieties screened for salt tolerance. Knowledge of the physiological effects of salinity on plants, both crop species and those species which are native to saline environments, has shown that there are no simple answers to the questions of how plants are damaged by salt and of how they survive it [53].

\subsection{Phenotypic screening}

Salt tolerance is complex genetically and physiologically [46]. The detection of salinity induced injuries, are very complex even under controlled conditions in terms of humidity, temperature and light etc. Moreover, it requires expensive and time-consuming tissue analysis. Physiological studies of rice suggest that a range of characteristics would increase the ability of the plant to cope with salinity. Those characteristics include such as low shoot sodium concentration, compartmentalization of salt in older rather 
than younger leaves, tolerance to salt within leaves and plant vigour [60]. Besides, any parameter which affects the transpiration rate, such as light intensity, temperature and humidity, can dramatically change a plant's susceptibility to salinity [61]. Salinity damage is not a determinate quantity, but can be expected to show extremely high genotype/ environment interaction. [62] also stated that there are visual symptoms of salt toxicity in tomato plant when salinity stress is combined with heat stress. There are different screening methods for different stages of growth. Early seedling stage manifest on the first leaf, followed by the second, and finally on the growing leaf. Salinity suppresses leaf elongation and formation of new leaves [63],[64]. Photosynthetic function and chlorophyll content were inversely proportional to salinity level. The screening technique developed is based on the ability of seedlings to grow in salinized nutrient solution [65].

Evaluation of vegetative and reproductive stages salinity tolerance is more difficult. Rice plant gains tolerance to salinity at reproductive stage. Plant height, root length and biomass decreases as a result of salinity. At reproductive stage, salinity causes an increase in sterile florets by affecting panicle initiation, spikelet formation, fertilization, and germination of pollen. Salinity also reduces panicle length, number of primary branches and spikelets per panicle, fertility and panicle weight, thus reducing grain yield [66]. When tested at vegetative and reproductive stages, grain yield per plant or pot is the best score for tolerance, but they may produce misleading results. It is impossible to get a good estimate of the total number of spikelets. Even in some tolerant varieties, some spikelets are malformed or aborted and sometimes they drop off before good spikelets mature [67]. There are also differences in term of ion concentrations. Some findings showed that a tolerant rice maintains a lower concentration of $\mathrm{Na}^{+}$and $\mathrm{CI}^{-}$, a higher concentration of $\mathrm{K}+$ and $\mathrm{Zn}+$, and lower Na-K and $\mathrm{Zn}-\mathrm{P}$ ratios in the shoot, compared with a salt-sensitive variety. Most of the crop plants including rice are considered as glycophytes and they have their specific thrsholds for the salt tolerance concentrations. The salt concentration they normally withstand is $1-40 \mathrm{mM}$ of sodium chloride. The Na-K ratio, which is the balance between $\mathrm{Na}^{+}$and $\mathrm{K}^{+}$in the shoot, could then be a valid criterion in measuring salinity tolerance in rice. Thus the parents have been classified according to the Na-K absorption ratio because of their metabolic interaction [47].

Among the disadvantages of phenotypic screening for desirable trait selection is, salt-tolerant phenotype selected at an early generation may not maintain its tolerance in subsequent generations and that this phenomenon is greatly affected by environmental factors [62]. Besides, overall performance or survival can be used to evaluate the salt resistance of a genotype, it is not the basis on which parents should be selected to construct a complex character through breeding [6].

\subsection{Genotypic screening}

With the advancement of modern biotechnology and genetic study, it has significantly helped in the selection and evaluation of salinity tolerance traits. Upon exposure to the stresses, many genes are induced and their products are thought to function as cellular protectants (e.g. proline and trehalose) of stress-induced damage [28],[59]. One of the useful tools in molecular research to study the genotypic of salinity tolerance is by identifying quantitative traits loci. One obvious use of QTL in plant breeding for salt tolerance is in marker-aided selection or marker-assisted selection, MAS [46]. There are QTLs that has clearly been established associating with aspects of germination, ion transport and yield of the plant.Salt tolerance is claimed as a multigenic trait and QTLs has been found, complying with the multigenic nature of salt tolerance. Several genes with polygenic nature ( $q S T 1$ and qST3 have been reported to be involved in abiotic stress tolerance including salinity [68]-[70].However, due to the complexity of salt tolerance mechanisms, so few QTL are identified [10] within any given genome [46].

QTLs for traits correlated were often mapped in the same chromosomal regions [24],[43]. Few QTLs associated with salinity tolerance have been identified in previous studies. Among them are located on chromosome 1, 3, 4, 12, 10 [13], 8 and 9 [24]. A major QTL, designated Saltol, was recently mapped. It accounted for more than $70 \%$ of the variation in salt uptake in this population. Marker-assisted backcrossing is currently used to incorporate this QTL into popular high-yielding varieties [1]. QTLs are also found to be as treatment-sensitive. Some QTL associated with aspects of fruit yield were found regardless of whether the plants were grown with or without salt [46]. However, the drawbacks in using marker-assisted breeding are "linkage drag" of undesirable traits due to the large size of regions of chromosomes identified by QTL [71] and the fact that environment and genetic background have a significant influence on the QTL that are identified [46].

\section{DEVELOPMENT OF SALT TOLERANCE CULTIVARS}

In [72], author(s) suggested five possible appropriate waysto develop salt-tolerant crops, such as: (i) develop halophytes as alternative crops; (ii) use interspecific hybridization to raise the tolerance of current crops; (iii) use the variation already present in existing crops; (iv) generate variation within existing crops by 
using recurrent selection, mutagenesis or tissue culture; and (v) breed for yield rather than tolerance [46]. Conventional breeding methods were adopted first in order to develop salt tolerant varieties like Shaheen basmati, Damodar CSR 1, Dasal CSR 2, Getu CSR 3 and Hamilton while CSR 10, CSR13 CSR23, CSR27, CSR30, CSR36, PSBRc48, PSBRc84, PSBRc86, PSBRc88 and NSIC Rc106 were developed through recombination breeding (IRRI).

Table 1. Origin based important sensitive rice varieties and salt tolerant varieties

\begin{tabular}{|c|c|c|c|c|c|c|c|}
\hline \multicolumn{4}{|c|}{ Sensitive Rice } & \multicolumn{4}{|c|}{ Salt Tolerant } \\
\hline Varieties & Origin & Subsp. & Literature & Varieties & Origin & Subsp. & Literature \\
\hline Tiqing & Australia & & [73] & Tarome-Molaei & & & [73] \\
\hline Koshihikari & Australia & japonica & [43] & Nona Bokra & India & Indica & [43] \\
\hline IR26 & & Indica & [74] & Jiucaiqing & & japonica & [74] \\
\hline MI 48 & & Indica & {$[75],[76]$} & CSR27 & & Indica & {$[75],[76]$} \\
\hline $77-170$ & & & [55] & $\mathrm{M}-20$ & & & [55] \\
\hline IR29 & & Indica & [36] & Pokkali & & Indica & {$[36],[77],[78]$} \\
\hline Azucena & Philippines & Japonica & [79] & Shaheen Basmati & Pakistan & & [80] \\
\hline IR36 & Philippines & Indica & [77] & Jingxi 17 & & Japonica & [81] \\
\hline Nipponbare & & & [77] & IR64 & Philippines & Indica & {$[79],[82],[83]$} \\
\hline Zhaiyeqing 8 & & Indica & [81] & IR5962 & & & [10] \\
\hline IR29 & Philippines & Indica & [78] & Tesanai 2 & & Indica & [84] \\
\hline $\mathrm{CB}$ & & Indica & [84] & Nipponbare & & & [85] \\
\hline Kasalath & & & [85] & AS996 & & & [86] \\
\hline Tarom Molaii & & & [82] & Tarommahali & & & {$[87],[88]$} \\
\hline Milyang 23 & Taiwan & Indica & [45] & Moroberekan & West African & Japonica & [89] \\
\hline Gihobyeo & & Japonica & [45] & & & & \\
\hline Binam & Iran & Japonica & [83] & & & & \\
\hline IR64 & Philippines & Indica & [86] & & & & \\
\hline Khazar & Iran & Japonica & {$[87],[88]$} & & & & \\
\hline Ilpumbyeo & & Japonica & [89] & & & & \\
\hline
\end{tabular}

Previous attempts to improve the salt tolerance of crops through conventional breeding programmes have met with very limited success, due to the complexity of the trait. Tolerance often shows the characteristics of a multigenic trait, with the QTLs associated with tolerance identified with ion transport under saline conditions [46]. The mechanism of salinity tolerance has to be understood first before a plant can be modified or bred for this trait [47]. Despite the variation in tolerance, new screening techniques, mutation, and anther culture techniques, salinity tolerance was successfully introduced into high-yielding plant types [13]. Some released varieties have demonstrated more than $50 \%$ yield advantage over current salt-sensitive varieties. The opportunity to improve salinity tolerance through the incorporation of useful genes appears very promising [1].

Rice hybrids are known to have high vegetative vigor and a stronger root system. These features enabled them to show better seedling tolerance for low temperature [22], salt tolerance [5]. These observations support the view that the salinity resistance of rice could be increased above the present level of observed phenotypic expression through the crossing of existing genotypes [6],[42].

\subsection{Conventional breeding}

Conventional plant breeding involves changing or combining the genes of a parental plant so that a new and better progeny variety can be developed. Most conventional breeding can be reduced to two fundamental steps. The first step is to generate a breeding population that is highly variable for desirable traits by identifying parents having traits of interest. The second fundamental step involves selection among the segregating progeny for individuals that combine the most useful traits of the parents with the fewest of their failings [90]. Some important salt tolerant varieties developed in recent years the world over, through conventional breeding techniques are shown in Table 2.

There were many attempts to enhance tolerance have involved conventional breeding programmes such as the use of in vitro selection, pooling physiological traits, interspecific hybridization, using halophytes as alternative crops [46]. The challenge is to combine the tolerance traits through breeding to develop stresstolerant cultivars. There have been successes in developing the salt tolerant cultivars in India where six varieties were developed and released as salt tolerant for cultivation [91]. Some of these varieties like CSR10, CSR13, CSR27, Narendra usar 2 and Narendra usar 3 have been used to reclaim saline soils in India [92]. There were 30 varieties developed conventionally for coastal saline and alkaline soils including CSR 2, CSR 3, CSR 13, CSR 22, CSR 23, CSR 26, CSR 27, CSR 30, Panvel 1, Panvel 2, Panvel 3, Pokkali Vytilla 1 and Vytilla 2 [70]. However, several attempts using traditional salt-tolerant parents such as Nona Bokra, Pokkali and Kalarata do not possess the level of tolerance found [13]. 
Table 2. Rice cultivars with improved salinity tolerance using conventional breeding techniques [70]

\begin{tabular}{|c|c|c|}
\hline Genotype/line/cultivarreleased & Releasingsource & Goodperformance \\
\hline $\begin{array}{l}\text { SR } 26 \text { B, CSR 1, CSR 2, CSR 3, Panvel 1, } \\
\text { Panvel 2, Panvel } 3\end{array}$ & $\begin{array}{l}\text { The Central Soil Salinity Research Institute (CSSRI), } \\
\text { Karnal, India }\end{array}$ & The coastal saline soil \\
\hline $\begin{array}{l}\text { Pokkali (in Kerala only), Vytilla } 1 \text { and Vytilla } \\
2\end{array}$ & $\begin{array}{l}\text { The Central Soil Salinity Research Institute (CSSRI), } \\
\text { Karnal, India }\end{array}$ & Sodic soil \\
\hline $\begin{array}{l}\text { Pokkali, Vytilla 1, Vytilla 2, Vytilla 3, Vytilla } \\
4 \text { and Vytilla } 5\end{array}$ & Kerala Agricultural University, India & Coastal regions \\
\hline $\begin{array}{l}\text { SR } 26 \text { B, Kalarata, Bhurarata, Panvel 1, Panvel } \\
\text { 2, and Panvel } 3 \text { and BTS } 24\end{array}$ & International Rice Research Institute, Philippines & Coastal regions \\
\hline $\begin{array}{l}\text { Savitri, Ponni, Swarnadhan, Mansarovar, } \\
\text { Salivahan and Pavizham }\end{array}$ & International Rice Research Institute, Philippines & $\begin{array}{l}\text { Shallow water } \\
\text { salinity conditions }\end{array}$ \\
\hline
\end{tabular}

Among problems associated with using physiological traits in plant breeding is that many individuals are needed to obtain a single assessment and the donors had too many undesirable traits that linked to salinity tolerance [6],[13]. The possibility of pooling physiological traits has been advocated for rice [6], screening methods evaluated [62] and the approach proved successful in generating salt-resistant lines [78]. The methodology does not require a deep knowledge of the genetics of traits merely that they display sufficient heritability and that suitable screening procedures can be developed [46]. Conventional breeding methods should not be reduced but be supplemented with studies in biotechnology as well as with studies on soil and water management. Through recent development in biotechnology, it seems make the breeders or scientists easier to select and produce their desirable traits to be incorporated through recombinant gene [78].

\subsection{Modern biotechnology}

Modern biotechnology techniques refer to utilizing the knowledge about fundamental physiology of plants such as genes, cells and tissues and manipulating them by utilizing different techniques for instance tissue culture, genetic engineering, recombinant DNA, hybridization, cloning and others. Some of the salt tolerant rice varieties developed through modern biotechnology techniques are mentioned in Table 3 . It is recommended to bring all important genes together in single plant so as to enhance the salinity tolerance levels [72].

Table 3. Rice cultivars with improved salinity tolerance using modern biotechnology techniques [70]

\begin{tabular}{|c|c|c|c|}
\hline Gene engineered & Source organism & Trait improved & Growth improved \\
\hline $\begin{array}{l}\text { Vacuolar } \mathrm{Na}^{+} / \mathrm{H}^{+} \\
\text {antiporter } \\
\text { AgNHX1 }\end{array}$ & Atriplex gmelini & $\begin{array}{l}\text { Activity of these } \\
\text { antiporters was } 8 \text {-fold } \\
\text { high }\end{array}$ & $\begin{array}{l}\text { Seedling survival increased } \\
\text { from } 51 \% \text { or } 81-100 \% \text {. }\end{array}$ \\
\hline $\begin{array}{l}\text { Vacuolar } \mathrm{Na}^{+} / \mathrm{H}^{+} \\
\text {antiporter gene } \\
\text { PqNHX1 }\end{array}$ & $\begin{array}{l}\text { Pennisetum } \\
\text { glaucum (L.) } \\
\text { R. Br. }\end{array}$ & $\begin{array}{l}\text { Well-developed root } \\
\text { System }\end{array}$ & $\begin{array}{l}\text { About } 81 \% \text { higher shoot and } \\
\text { root lengths. }\end{array}$ \\
\hline $\begin{array}{l}\text { Vacuolar } \mathrm{Na}^{+} / \mathrm{H}^{+} \\
\text {antiporter gene } \\
\text { OsNHX1 }\end{array}$ & $\begin{array}{l}\text { Wild rice (Oryza } \\
\text { sativa L.) }\end{array}$ & $\begin{array}{l}\text { High accumulation of } \\
\mathrm{Na}^{+} \text {and low } \mathrm{K}^{+}\end{array}$ & $\begin{array}{l}\text { Tolerate salinity level up to } 0.2 \\
\text { M where wild plants Died }\end{array}$ \\
\hline $\begin{array}{l}\Delta 1 \text {-pyrroline-5- } \\
\text { carboxylate } \\
\text { synthetase } \\
(P 5 C S)\end{array}$ & $\begin{array}{l}\text { Moth bean (Vigna } \\
\text { aconitifolia) }\end{array}$ & $\begin{array}{l}\text { Transgenic plants } \\
\text { accumulated more } \\
\text { proline under both } \\
\text { saline and non-saline } \\
\text { conditions }\end{array}$ & $\begin{array}{l}\text { Shoot fresh weight was } \\
\text { increased from } 30-93 \% \text { and } \\
\text { root fresh weight } 37-74 \% \\
\text { under } 200 \mathrm{mM} \mathrm{NaCl} \text { as } \\
\text { compared to those in wild type }\end{array}$ \\
\hline $\begin{array}{l}\mathrm{Na}^{+} / \mathrm{H}^{+} \text {antiporter } \\
\text { SOD2 }\end{array}$ & Yeast & $\begin{array}{l}\text { Transgenic plants } \\
\text { accumulated higher } \mathrm{K}^{+}, \mathrm{Ca}^{2+}, \mathrm{Mg}^{2+} \text { and lower } \mathrm{Na}^{+} \text {in their } \\
\text { shoots as compared to respective non-transformed controls }\end{array}$ & $\begin{array}{l}\text { Transgenic plants showed good } \\
\text { performance under } \\
\text { saline conditions }\end{array}$ \\
\hline$O P B P 1$ gene & Tobacco & $\begin{array}{l}\text { Transgenic plants showed } \\
\text { high resistance against } \\
\text { salt and disease }\end{array}$ & \\
\hline
\end{tabular}




\subsubsection{QTL identifications}

Genetic dissection of salinity tolerance traits is done exploiting Quantitative Trait Loci (QTLs) mapping technique. This is accomplished by crossing two parental lines distinct in traits of interest. A stress sensitive and stress tolerant parent is crossed to get populations with enhanced tolerance and sensitivity. Salinity tolerance of rice is known being controlled by certain genes in complex genetic interactions and it is claimed as multigenic traits. The multigenic nature of salt tolerance has clearly been established and QTL associated with aspects of germination, ion transport and yield. With identification of various QTL which believed attributed to the salt tolerance, it can help the efforts to produce new rice cultivars with desirable traits [24],[78].

Hundreds of QTLs have been identified for salinity tolerance in economically important crop plants but quite a few have been confirmed for enhancing salinity tolerance in the field. Among all these crops, rice has received attention for improving salinity tolerance using modern breeding techniques. For example, [93] fine mapped the Saltol QTL in rice genome and identified QTLs associated with salt tolerance using Recombinant Inbred Lines (RILs) derived from IR29 and Pokkali. Its contribution to phenotypic variation was $43 \%$ for seedling shoot $\mathrm{Na}-\mathrm{K}$ ratio [78].

The [94] detected 3 major QTLs associated with salinity tolerance on chromosomes 1, 8 and 10 with phenotypic variance of $12.5,29$ and $20.2 \%$ respectively. $\mathrm{F}_{2}$ breeding population was used in this case. It was derived from a highly salt tolerant IR6920-3B-22-2-1 (NSIC Rc106) and moderately salt tolerant BRRI dhan40. Three QTLs for survival days of seedlings (SDSs) under stress were detected on 3 chromosomes 1, 6 and 7 explaining a phenotypic variation ranging from 13.9-18\% [43].

Plants undergoing salinity stress experience cellular osmotic adjustments and ion exclusion. $\mathrm{Na}^{+} / \mathrm{K}^{+}$ homeostasis plays critical role in ameliorating the damaging effects of $\mathrm{Na}^{+}$. Several QTLs have been identified controlling $\mathrm{Na}^{+} / \mathrm{K}^{+}$homeostasis. [76] have mapped 25 major QTLs on chromosomes 1, 2, 3 and 8 including one QTL for seedling salt injury score, 9 for Na${ }^{+}$concentration, 3 for $\mathrm{K}^{+}$concentration and 4 for $\mathrm{Cl}^{-}$ concentration in leaf and stem. High quality rice genome sequence (IRGSP) has made it possible to clone the genes underlying QTLs for salt tolerance [95]. The [96] have cloned a gene SKC1 that regulates $\mathrm{Na}^{+} / \mathrm{K}^{+}$ homeostasis in salt tolerant rice genotype. The [97] have identified QTLs for physiological traits determining salt tolerance in rice. They have identified QTLs directly governing sodium uptake, potassium uptake and sodium: potassium selectivity. In [75], author(s) have combined QTL mapping and transcriptome profiling in order to identify salt tolerance genes using RILs derived from CSR27a salt tolerant variety and MI48 a salt sensitive variety and reported 8 QTLs for salt ion concentrations on rice chromosomes 1,8 and 12 .

In an attempt to minimise the environmental effects in salt tolerance [74] using RILs at seedling stage in rice have identified QTLs for salt tolerance including $\mathrm{Na}^{+} / \mathrm{K}^{+}$ratios. [73] identified 14 QTLs using SSR on chromosomes 1, 3, 4, 5, 6 and 8 for salt tolerance traits in rice. [98] reported a QTL RG13 on chromosome 11 associated significantly with salt tolerance using RILs. One QTL Std on chromosome 1. Similarly [99] reported 12 QTLs for salt ion concentration on chromosomes 1, 2, 3, 4, 7 and 11 respectively.

All these identified, fine mapped and cloned QTLs can be utilised in modern biotechnology techniques to improve the salinity tolerance in crop plants. Marker assisted selection is a promising techniques bringing genes of interest into plants. However, the drawbacks in using marker-assisted breeding are 'linkage drag' of undesirable traits due to the large size of regions of chromosomes identified by QTL [71] and the fact that environment and genetic background have a significant influence on the QTL that are identified [46].

\subsubsection{Transgene}

Recent research has shown that rice, transformed to overexpress genes that brought about the synthesis of trehalose, contained a reduced concentration of $\mathrm{Na}$ in the shoot and grew better than nontransformed (control) plants when in the presence of $100 \mathrm{mM} \mathrm{NaCl}$. However, there is a risk of this. Although trehalose is commonly present in bacteria, fungi and insects, its concentration in plants is very low and it may even be toxic: recent evidence suggests that this toxicity may stem from its role in the regulation of carbon metabolism [46],[100]. In spite of the complexity of salt tolerance, there are also claims that the transfer of a single or a few genes can increase the tolerance of plants to saline conditions. Evaluation of such claims reveals that, of the 68 papers produced between 1993 and early 2003, only 19 report quantitative estimates of plant growth [46]. Transgenic technology will undoubtedly continue to aid the search for the tolerance mechanisms, but the complexity of the trait is will be the challenge for this technique to succeed [46].

\subsubsection{Haploid breeding}

Haploid breeding is another useful tool for breeding. Double haploid (DH) lines are generated either through anther culture (AC) or chromosome elimination methods. DH lines are excellent materials for rice 
breeding and genetic research because of their homozygosity and uniformity. [79] detected 7 QTLs for seedling traits under salt stress using a double haploid population derived from a cross between IR64 and Azucena, and a QTL for root length had 18.9\% contribution to phenotypic variation. [81] identified genes underlying a total of 8 QTLs for salt tolerance using double haploid population derived from a cross between indica variety ZYQ8 and japonica variety JX17. DH breeding saves times to obtain the homozygous state as well as for evaluating the yield and other quantitative traits compared to normal self-pollinating methods [71]. Development by using conventional breeding can take $8-10$ year to obtain a promising salinitytolerant line. However, by using DH culture, the period could be shortened to just 3 years. The cultivar, which is the first DH derived line from indica-indica cross has been released in Philippines and India [78].

\subsubsection{Somaclonal variation}

Somaclonal variation is another promising field along with tissue culture techniques to enhance salinity tolerance in crop plants. The variability is induced by in vitro mutagenesis and somaclonal variation to improve the salt tolerance in plants. Cell and tissue culture approaches are quite feasible in achieving significant salinity tolerance levels in plants. This is accomplished by in vitro selection of the mutant lines and by carrying it on with regenerationSomacl-onal variation method also has been carried out to produce a better plant. A Somaclonal variant of Pokkali, a cultivar which is highly salt-tolerant but produce low yield, has shown that the variants contain desirable levels of all tested characteristics. They retain their salinity tolerance equal to Pokkali, has vigorous growth unlike Pokkali and is semi-dwarf - an essential trait in increasing yield potential without lodging [78]. Genotype difference in Callus induction and subsequent regeneration of plant has not been understood well [101].

\section{CONCLUSION}

Based on the progress and our knowledge in developing salinity tolerant crops discussed above, it is quite obvious that goal is yet to be achieved. A lot more still needs to be done. Combining different strategies would be very promising. Combining classical breeding techniques and modern biotechnology techniques would help filling the gaps. As it is mentioned above that salt stress is not the only stress that plants are facing at one time. The drought and temperature stress could also be the reasons behind salt stress. The cross talks and noise going on could mislead the results so there is a need to minimise the effects of other stresses. This has also lead to the little success in exploiting the major QTLs discovered so far. Moreover the major QTLs discovered and identified so far, have been testes in greenhouses in small pots providing good conditions. This is why so many MAS programs did not go well and the major QTLs studied could not provide the salinity tolerance as predicted. Such QTLs should also be tested in the fields before using them for any breeding programs.

\section{REFERENCES}

[1] Q. Jing, et al., "Exploring options to combine high yields with high nitrogen use efficiencies in irrigated rice in China," European Journal of Agronomy, vol/issue: 26(2), pp. 166-77, 2007.

[2] Khush, et al., "Rice biotechnology," Int. Rice Res. Inst. 1991.

[3] L. H. Ziska, et al., "Chapter Three-Weedy (Red) Rice: An Emerging Constraint to Global Rice Production," Advances in agronomy, vol. 129, pp. 181-228, 2015.

[4] J. Bennett, et al., "Capital \& counties report: Japanese construction industry," Centre for Strategic Studies in Construction, University of Reading, 1987.

[5] J. A. Schaar, et al., "Terminology for high-risk and vulnerable coronary artery plaques," European heart journal, vol/issue: 25(12), pp. 1077-82, 2004.

[6] A. R. Yeo, et al., "Screening of rice (Oryza sativa L.) genotypes for physiological characters contributing to salinity resistance, and their relationship to overall performance," Theoretical and Applied Genetics, vol/issue: 79(3), pp. 377-84, 1990.

[7] M. C. Shannon, "Adaptation of plants to salinity," Advances in agronomy, vol. 60, pp. 75-120, 1997.

[8] R. Munns \& M. Tester, "Mechanisms of salinity tolerance," Annu Rev Plant Biol., vol. 59, pp. 651-81, 2008.

[9] N. Tuteja, "Chapter Twenty-four-mechanisms of high salinity tolerance in plants," Methods in enzymology, vol. 428, pp. 419-38, 2007.

[10] T. J. Flowers, et al., "QTL: their place in engineering tolerance of rice to salinity," Journal of Experimental Botany, vol/issue: 51(342), pp. 99-106, 2000.

[11] P. S. Rao, et al., "Reproductive stage tolerance to salinity and alkalinity stresses in rice genotypes," Plant Breeding, vol/issue: 127(3), pp. 256-61, 2008.

[12] Pessarakli \& I. M. Szabolcs, "Soil salinity and sodicity as particular plant-crop stress factors. Handbook of plant and crop stress. revised and expanded," Marcel Dekker, Inc., New York, 1999. 
[13] G. B. Gregorio, "Progress in breeding for trace minerals in staple crops," The Journal of nutrition, vol/issue: 132(3), pp. 500S-2S, 2002.

[14] J. L. Largier, “Tidal intrusion fronts,” Estuaries, vol/issue: 15(1), pp. 26-39, 1992.

[15] R. D. Graham, et al., "Addressing micronutrient malnutrition through enhancing the nutritional quality of staple foods: principles, perspectives and knowledge gaps," Advances in Agronomy, vol. 70, pp. 77-142, 2001.

[16] R. Wassmann, et al., "Sea level rise affecting the Vietnamese Mekong Delta: water elevation in the flood season and implications for rice production," Climatic Change, vol/issue: 66(1-2), pp. 89-107, 2004.

[17] A. Smajgl, et al., "Responding to rising sea levels in the Mekong Delta," Nature Climate Change, vol/issue: 5(2), pp. 167-74, 2015.

[18] Le Dang, et al., "Farmers' perceptions of climate variability and barriers to adaptation: lessons learned from an exploratory study in Vietnam," Mitigation and adaptation strategies for global change, vol/issue: 19(5), pp. 53148, 2014.

[19] D. Conway \& J. Mustelin, "Strategies for improving adaptation practice in developing countries," Nature Climate Change, vol/issue: 4(5), pp. 339-42, 2014.

[20] L. Zeng, \& M. C. Shannon, "Salinity effects on seedling growth and yield components of rice," 2000.

[21] H. Walia, et al., "Genome-wide transcriptional analysis of salinity stressed japonica and indica rice genotypes during panicle initiation stage," Plant molecular biology, vol/issue: 63(5), pp. 609-23, 2007.

[22] M. Akbar, et al., "Breeding for salinity tolerance in rice," IRRI Saturday Seminar, Los Banos, Laguna (Philippines), May 1985, 1985.

[23] J. K. Zhu, "Plant salt tolerance," Trends in plant science, vol/isue: 6(2), pp. 66-71, 2001.

[24] M. A. Javed, et al., "Identification of QTLs for morph-physiological traits related to salinity tolerance at seedling stage in indica rice," Procedia Environmental Sciences, vol. 8, pp. 389-95, 2011.

[25] M. Z. Yao, et al., "Inheritance and QTL mapping of salt tolerance in rice," Rice Sci., vol/issue: 12(1), pp. 25-32, 2005.

[26] R. Laik, et al., "Integration of conservation agriculture with best management practices for improving system performance of the rice-wheat rotation in the Eastern Indo-Gangetic Plains of India," Agriculture, Ecosystems \& Environment, vol. 195, pp. 68-82, 2014.

[27] H. J. Bohnert \& R. G. Jensen, "Strategies for engineering water-stress tolerance in plants," Trends in Biotechnology, vol/issue: 14(3), pp. 89-97, 1996.

[28] E. A. Bray, "Plant responses to water deficit," Trends in plant science, vol/issue: 2(2), pp. 48-54, 1997.

[29] W. Wang, et al., "Plant responses to drought, salinity and extreme temperatures: towards genetic engineering for stress tolerance," Planta, vol/issue: 218(1), pp. 1-14, 2003.

[30] A. K. Parida \& A. B. Das, "Salt tolerance and salinity effects on plants: a review," Ecotoxicology and environmental safety, vol/issue: 60(3), pp. 324-49, 2005.

[31] V. Chinnusamy, et al., "Understanding and improving salt tolerance in plants," Crop Science, vol/issue: 45(2), pp. 437-48, 2005.

[32] R. Kumari, et al., "Seed culture of rice cultivars under salt stress," Int J Pure App Biosci., vol/issue: 3(1), pp. 191202, 2015.

[33] K. M. A. Zinnah, et al., "In vitro regeneration and screening for salt tolerance in rice (Oryza sativa L.)," Int Res $J$ Biol Sci., vol. 2, pp. 29-36, 2013.

[34] N. A. Chachar, et al., "Screening for salt tolerant rice (Oryza sativa L.) genotypes at early seedling stage," Journal of Agricultural Technology, vol/issue: 10(1), pp. 265-75, 2014.

[35] S. J. Roy, et al., "Salt resistant crop plants," Current Opinion in Biotechnology, vol. 26, pp. 115-24, 2014.

[36] G. B. Gregorio, et al., "Screening rice for salinity tolerance," International Rice Research Institute discussion paper series, vol. 22, 1997.

[37] M. L. Dionisio-Sese \& S. Tobita, "Effects of salinity on sodium content and photosynthetic responses of rice seedlings differing in salt tolerance," Journal of Plant Physiology, vol/issue: 157(1), pp. 54-8, 2000.

[38] M. T. Campbell, et al., "Integrating image-based phenomics and association analysis to dissect the genetic architecture of temporal salinity responses in rice," Plant physiology, vol/issue: 168(4), pp. 1476-89, 2015.

[39] J. A. Bac-Molenaar, et al., "Genome-wide association mapping of growth dynamics detects time-specific and general quantitative trait loci," Journal of experimental botany, pp. 176, 2015.

[40] T. B. Brown, et al., "Trait Capture: genomic and environment modelling of plant phenomic data," Current opinion in plant biology, vol. 18, pp. 73-9, 2014.

[41] R. Karan, et al., "Salt stress induced variation in DNA methylation pattern and its influence on gene expression in contrasting rice genotypes," PloS one, vol/issue: 7(6), pp. e40203, 2012.

[42] A. R. Yeo, et al., "Selection for physiological characters - examples from breeding for salt tolerance Plants under Stress," Cambridge University Press, 1989.

[43] H. X. Lin, et al., "QTLs for Na+ and K+ uptake of the shoots and roots controlling rice salt tolerance," Theoretical and Applied Genetics, vol/issue: 108(2), pp. 253-60, 2004.

[44] D. M. Oosterhuis, et al., "The physiology of potassium in crop production," Advances in Agronomy, vol. 126, pp. 203-33, 2014.

[45] S. Y. Lee, et al., "Mapping QTLs related to salinity tolerance of rice at the young seedling stage," Plant Breeding, vol/issue: 126(1), pp. 43-6, 2007.

[46] T. J. Flowers, "Improving crop salt tolerance," Journal of Experimental botany, vol/issue: 55(396), pp. 307-19, 2004. 
[47] G. B. Gregorio \& D. Senadhira, "Genetic analysis of salinity tolerance in rice (Oryza sativa L.)," Theoretical and Applied Genetics, vol/issue: 86(2-3), pp. 333-8, 1993.

[48] K. S. Lee, et al., "Salinity tolerance of japonica and indica rice (Oryza sativa L.) at the seedling stage," Planta, vol/isssue: 216(6), pp. 1043-6, 2003.

[49] N. K. Fageria, "Salt tolerance of rice cultivars," Plant and soil, vol/issue: 88(2), pp. 237-43, 1985.

[50] D. P. Heenan, et al., "Salinity tolerance in rice varieties at different growth stages," Animal Production Science, vol/issue: 28(3), pp. 343-9, 1988

[51] El Mokhtar, et al., "Effect of different levels of salinity on germination and early seedling growth of three rice varieties cultivated in Mauritania," International Journal of Agriculture and Crop Sciences, vol/issue: 8(3), pp. $346,2015$.

[52] A. Shereen, et al., "Salinity induced metabolic changes in rice (Oryza sativa L.) seeds during germination," Pak $J$ Bot., vol/issue: 43(3), pp. 1659-61, 2011.

[53] U. Deinlein, "Plant salt-tolerance mechanisms," Trends in plant science, vol/issue: 19(6), pp. 371-9, 2014.

[54] V. D. Taffouo, et al., "Effects of salinity stress on seedlings growth, mineral nutrients and total chlorophyll of some tomato (Lycopersicum esculentum L.) cultivars," African Journal of Biotechnology, vol/issue: 9(33), 2013.

[55] H. Fan, et al., "Effect of different potassium levels on the growth and photosynthesis of sweet sorghum seedlings under salt stress," Advances in Energy, Environment and Materials Science: Proceedings of the International Conference on Energy, Environment and Materials Science (EEMS 2015), Guanghzou, PR China, August 25-26, 2015; 2016.

[56] D. Bhusan, et al., "Improvement of salt tolerance in rice (Oryza sativa L.) by increasing antioxidant defense systems using exogenous application of proline," Australian Journal of Crop Science, vol/issue: 10(1), pp. 50, 2016.

[57] G. A. D. Miller, et al., "Reactive oxygen species homeostasis and signalling during drought and salinity stresses," Plant, cell \& environment, vol/issue: 33(4), pp. 453-67, 2010.

[58] T. Yamaguchi \& E. Blumwald, "Developing salt-tolerant crop plants: challenges and opportunities," Trends in plant science, vol/issue: 10(12), pp. 615-20, 2005.

[59] S. J. Oh, et al., "Arabidopsis CBF3/DREB1A and ABF3 in transgenic rice increased tolerance to abiotic stress without stunting growth," Plant Physiology, vol/issue: 138(1), pp. 341-51, 2005.

[60] D. M. Almeida, et al., "Screening for Abiotic Stress Tolerance in Rice: Salt, Cold, and Drought," Environmental Responses in Plants: Methods and Protocols, vol. 155, pp. 82, 2016.

[61] M. M. Chaves, et al., "Photosynthesis under drought and salt stress: regulation mechanisms from whole plant to cell," Annals of botany, vol/issue: 103(4), pp. 551-60, 2009.

[62] R. M. Rivero, et al., "The combined effect of salinity and heat reveals a specific physiological, biochemical and molecular response in tomato plants," Plant, cell \& environment, vol/issue: 37(5), pp. 1059-73, 2014.

[63] I. G. B. Arsa, et al., "Evaluation of Grain Yield and Aroma of Upland Rice (Pare Wangi Var.) as Response to Soil Moisture and Salinity," Current Agriculture Research Journal, vol/issue: 4(1), 2016.

[64] G. Céccoli, et al., "Plasticity in sunflower leaf and cell growth under high salinity," Plant Biology, vol/issue: 17(1), pp. 41-51, 2015.

[65] B. Faiyue, et al., "A new screening technique for salinity resistance in rice (Oryza sativa L.) seedlings using bypass flow," Plant, cell \& environment, vol/issue: 35(6), pp. 1099-108, 2012.

[66] M. Thitisaksakul, et al., "Effects of timing and severity of salinity stress on rice (Oryza sativa L.) yield, grain composition, and starch functionality," Journal of agricultural and food chemistry, vol/issue: 63(8), pp. 2296-304, 2015.

[67] B. Sánchez, et al., "Temperatures and the growth and development of maize and rice: a review," Global change biology, vol/issue: 20(2), pp. 408-17, 2014.

[68] M. A. Causse, et al., "Saturated molecular map of the rice genome based on an interspecific backcross population," Genetics, vol/issue: 138(4), pp. 1251-74, 1994.

[69] K. K. Jena \& D. J. Mackill, "Molecular markers and their use in marker-assisted selection in rice," Crop Science, vol/issue: 48(4), pp. 1266-76, 2008.

[70] M. Shahbaz \& M. Ashraf, "Improving salinity tolerance in cereals," Critical reviews in plant sciences, vol/issue: 32(4), pp. 237-49, 2013.

[71] V. A. Martinez, et al., "On the use of double haploids for detecting QTL in outbred populations," Heredity, vol/issue: 88(6), pp. 423-31, 2002.

[72] T. J. Flowers \& A. R. Yeo, "Breeding for salinity resistance in crop plants: where next?" Functional Plant Biology, vol/issue: 22(6), pp. 875-84, 1995.

[73] J. Ahmadi \& M. H. Fotokian, "Identification and mapping of quantitative trait loci associated with salinity tolerance in rice (Oryza Sativa) using SSR markers," Iranian Journal of Biotechnology, vol/issue: 9(1), pp. 21-30, 2011.

[74] Z. Wang, et al., "Identification of QTLs with main, epistatic and QTL× environment interaction effects for salt tolerance in rice seedlings under different salinity conditions," Theoretical and Applied Genetics, vol/issue: 125(4), pp. 807-15, 2012.

[75] A. Pandit, et al., "Combining QTL mapping and transcriptome profiling of bulked RILs for identification of functional polymorphism for salt tolerance genes in rice (Oryza sativa L.)," Molecular Genetics and Genomics, vol/issue: 284(2), pp. 121-36, 2010. 
[76] M. H. M. Ammar, et al., "Mapping of QTLs controlling Na+, $\mathrm{K}+$ and $\mathrm{CI}-$ ion concentrations in salt tolerant indica rice variety CSR27," Journal of Plant Biochemistry and Biotechnology, vol/issue: 18(2), pp. 139-50, 2009.

[77] F. M. Abbasi \& S. Komatsu, "A proteomic approach to analyze salt-responsive proteins in rice leaf sheath," Proteomics, vol/issue: 4(7), pp. 2072-81, 2004.

[78] P. Bonilla, et al., "RFLP and SSLP mapping of salinity tolerance genes in chromosome 1 of rice (Oryza sativa L.) using recombinant inbred lines," Philippine Agricultural Scientist (Philippines), 2002.

[79] S. R. Prasad, et al., "Molecular mapping of quantitative trait loci associated with seedling tolerance to salt stress in rice (Oryza sativa L.)," Current Science, vol/issue: 78(2), pp. 162-4, 2000.

[80] A. Sakina, et al., "Genetic Variation for Salinity Tolerance in Pakistani Rice (Oryza sativa L.) Germplasm," Journal of Agronomy and Crop Science, vol/issue: 202(1), pp. 25-36, 2016.

[81] J. Gong, et al., "Identification of salt-tolerance QTL in rice (Oryza sativa L.)," Chinese Science Bulletin, vol/issue: 44(1), pp. 68-71, 1999.

[82] M. H. Fotoukian, et al., "QTL mapping of genes affecting salt tolerance in rice (Oryza sativa L.) using microsatellite markers," 2005.

[83] J. P. Zang, et al., "Dissection of genetic overlap of salt tolerance QTLs at the seedling and tillering stages using backcross introgression lines in rice," Science in China Series C: Life Sciences, vol/issue: 51(7), pp. 583-91, 2008.

[84] M. S. Masood, "Mapping quantitative trait loci (QTLs) for salt tolerance in rice (Oryza sativa) using RFLPs," Pak $J$ Bot., vol/issue: 36(4), pp. 825-34, 2004.

[85] H. Takehisa, "Identification of quantitative trait loci for plant growth of rice in paddy field flooded with salt water," Field Crops Research, vol/issue: 89(1), pp. 85-95, 2004.

[86] N. T. Lang, et al., "Molecular mapping and marker-assisted selection for salt tolerance in rice (Oryza sativa L.)," 2008.

[87] H. Sabouri \& A. Sabouri, "New evidence of QTLs attributed to salinity tolerance in rice," African Journal of Biotechnology, vol/issue: 7(24), 2008.

[88] H. Sabouri, et al., "QTLs mapping of physiological traits related to salt tolerance in young rice seedlings," Biologia Plantarum, vol/issue: 53(4), pp. 657-62, 2009.

[89] D. M. Kim, at al., "Mapping QTLs for salt tolerance in an introgression line population between japonica cultivars in rice," Journal of Crop Science and Biotechnology, vol/issue: 12(3), pp. 121-8, 2009.

[90] R. Manshardt, "Crop Improvement by Conventional Breeding or Genetic Engineering: How Different Are They?," 2004.

[91] R. K. Singh, et al., "Salt tolerant rice varieties and their role in reclamation programme in Uttar Pradesh," Indian Farming, pp. 6-10, 2004.

[92] P. D. Sankar, et al., "Rice breeding for salt tolerance," Research in Biotechnology, vol/issue: 2(2), 2011.

[93] M. J. Thomson, et al., "Characterizing the Saltol quantitative trait locus for salinity tolerance in rice," Rice,vol/issue: 3(2-3), pp. 148-60, 2010.

[94] M. R. Islam, et al., "QTL mapping for salinity tolerance at seedling stage in rice," Emirates Journal of Food and Agriculture, vol/issue: 23(2), pp. 137, 2011.

[95] A. H. Price, "Believe it or not, QTLs are accurate!," Trends in plant science, vol/issue: 11(5), pp. 213-6, 2006.

[96] Z. H. Ren, et al., "A rice quantitative trait locus for salt tolerance encodes a sodium transporter," Nature genetics, vol/issue: 37(10), pp. 1141-6, 2005.

[97] M. L. Koyama, et al., "Quantitative trait loci for component physiological traits determining salt tolerance in rice," Plant Physiology, vol/issue: 125(1), pp. 406-22, 2001.

[98] H. Lin, et al., "Identification of QTL for salt tolerance in rice via molecular markers," Zhongguo shuidao kexue, vol/issue: 12(2), pp. 72-8, 1997.

[99] L. Cheng, et al., "Identification of salt-tolerant QTLs with strong genetic background effect using two sets of reciprocal introgression lines in rice," Genome, vol/issue: 55(1), pp. 45-55, 2011.

[100] A. K. Garg, et al., "Trehalose accumulation in rice plants confers high tolerance levels to different abiotic stresses," Proceedings of the National Academy of Sciences, vol/issue: 99(25), pp. 15898-903, 2002.

[101] A. H. Kabir, et al., "Indirect organogenesis and somaclonal variation in four rice cultivars of Bangladesh," J Appl Sci Res., vol/issue: 4(4), pp. 45-458, 2008.

\section{BIOGRAPHIES OF AUTHORS}

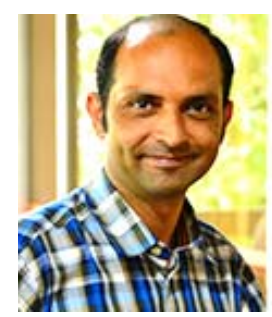

Samiullah Khan (First Author),

Ph.D Scholar

Faculty of Biosciences and Medical Engineering (FBME), Universiti Teknologi Malaysia (UTM), Skudai, 81310, Johor Bahru, Johor Darul Ta’zim, Malaysia.

Email: samipisces@gmail.com 


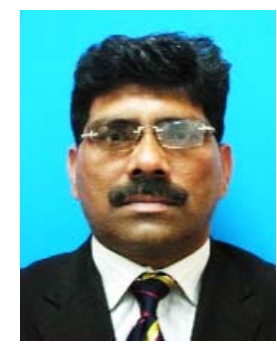

Dr. Muhammad Arshad Javed (Corresponding Author)

Senior Lecturer

Faculty of Biosciences and Medical Engineering (FBME), Universiti Teknologi Malaysia (UTM), Skudai, 81310, Johor Bahru, Johor Darul Ta'zim, Malaysia.

Email: majaved@fbb.utm.my

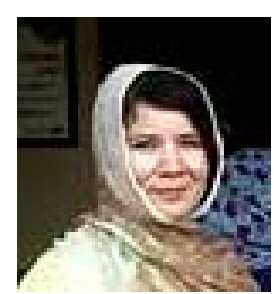

Nusrat Jahan (Co-Author)

Ph.D Scholar

Faculty of Biosciences and Medical Engineering (FBME), Universiti Teknologi Malaysia (UTM), Skudai, 81310, Johor Bahru, Johor Darul Ta'zim, Malaysia.

Email: nusrat.jahanbuitems@gmail.com

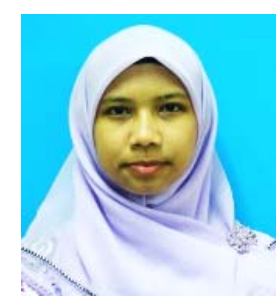

Dr. Fazilah Abd Manan (Co-Author)

Senior Lecturer

Faculty of Biosciences and Medical Engineering (FBME), Universiti Teknologi Malaysia (UTM), Skudai, 81310, Johor Bahru, Johor Darul Ta'zim, Malaysia.

Email: fazilah@fbb.utm.my 